\title{
The Effect of YanBang Dishes Selection Attributes and SNS Information Characteristics in China on Brand Loyalty: Focusing on the Mediating Effect of Consumer Satisfaction
}

\author{
중국의 염방채 선택속성과 SNS 정보특성이 브랜드 \\ 충성도에 미치는 영향: 소비자 만족도 매개효과를 \\ 중심으로 \\ Eun Hee Kim ${ }^{1}$, Chen Yilong ${ }^{2}$ \\ 김은희 ${ }^{1}$, 진이용 2 \\ ${ }^{I}$ Assistant Professor, Division of Advertising \& PR Communications, Mokwon University, Korea, \\ eunhee0103@mokwon.ac.kr \\ ${ }^{2}$ University Personnel, Sichuan University of Science and Engineering,China, 136400475@qq.com
}

Corresponding author: Chen Yilong

\begin{abstract}
YanBang Dishes is a traditional food enjoyed by the citizens of Zigong, Sichuan, China. Therefore, in this study, it was verified whether the attribute of selecting YanBang Dishes, a traditional food representing Tsugong City, and the characteristics of SNS information that can confirm and share YanBang Dishes information had a positive $(+)$ effect on consumer satisfaction and brand loyalty. The respondents of the study consisted of consumers who have eaten YanBang Dishes within the last 6 months among residents of Zigong City, Sichuan Province. For statistical analysis, frequency analysis, factor analysis, multiple regression analysis, and mediation regression analysis were performed. As a result of checking the YanBang Dishes selection attributes, four factors were derived: quality, tradition, service, and relevance. The SNS information characteristics were derived as reliability, interactivity, usefulness, and up-to-datedness. The results of testing the research hypothesis with the above factors are as follows. First, it was confirmed that the YanBang Dishes selection attribute had a positive $(+)$ effect on consumer satisfaction and brand loyalty. Second, it was confirmed that SNS information characteristics had a positive $(+)$ effect on consumer satisfaction and brand loyalty. Third, it was confirmed that customer satisfaction had a positive $(+)$ effect on brand loyalty. Fourth, among the selection attribute factors of YanBang Dishes, service and appropriateness completely mediate on consumer satisfaction and have a positive $(+)$ effect on brand loyalty. First, as a result of checking the YanBang Dishes selection attributes, four factors were derived: quality, tradition, service, and relevance. SNS information characteristics were derived as reliability, interactivity, usefulness, and up-to-dateness. The results of testing the research hypothesis with the above factors are as follows. First, it was confirmed that the YanBang Dishes selection attribute had a positive $(+)$ effect on consumer satisfaction and brand loyalty. Second, it was confirmed that SNS information characteristics had a positive $(+)$ effect on consumer satisfaction and brand loyalty. Third, it was confirmed that customer satisfaction had a positive $(+)$ effect on brand loyalty. Fourth, among the selection attribute factors of YanBang Dishes, service and appropriateness completely mediate on consumer satisfaction and have a positive $(+)$ effect
\end{abstract}

Received: August 20, 2021; 1st Review Result: October 06, 2021; 2nd Review Result: November 21, 2021

Accepted: December 31, 2021

*This thesis is based on the second author's 2021 master's thesis. 
on brand loyalty.

Keywords: YanBang Dishes Selection Attributes, SNS Information Characteristics, Satisfaction, Loyalty

요약: 중국 쓰촨성 쯔궁지역의 전통음식 염방채를 선택하는 속성과 염방채 정보를 제공하는 $\mathrm{SNS}$ 특성이 소비자 만족도와 브랜드 충성도에 미치는 영향을 확인하였다. 응답자 표본은 최근 6 개월 이내 염방채를 먹어 본 소비자들이다. 연구가설 검증 결과는 다음과 같다. 첫째, 염방채 선택속성과 SNS 정보특성은 소비자 만족도와 브랜드 충성도에 정(+)의 영향을 미치는 것으로 확인하였다. 둘째, 소비자 만족도는 브랜드 충성도에 정 $(+)$ 의 영향을 미치는 것으로 확인하였다. 셋째, 염방채의 선택속성 요인 중 서비스와 적절성은 소비자 만족도에 완전 매개하여 브랜드 충성도에 정 $(+)$ 의 영향을 미치는 것으로 확인하였다. 그러나 염방채의 선택속성 중 품질과 전통성은 소비자 만족도에 부분 매개하여 브랜드 충성도에 정(+)의 영향을 미치는 것으로 확인하였다. 넷째, SNS 정보특성 요인 중 신뢰성과 최신성은 소비자 만족도에 완전 매개하여 브랜드 충성도에 정 $(+)$ 의 영향이 미치는 것으로 확인하였다. 그러나 SNS 정보특성 요인 중 상호작용성과 유용성은 소비자 만족도를 부분 매개하여 브랜드 충성도에 정 $(+)$ 의 영향이 미치는 것으로 확인하였다. 이상의 연구는 중국의 전통음식인 염방채 선택속성과 염방채 정보를 얻고 소통하는 SNS 정보특성이 소비자 만족도를 매개하여 염방채 브랜드 충성도에 영향이 미친다는 것을 검증하였다는 학문적 함의를 갖는다. 또한 전통음식으로써 염방채 브랜드를 활성화 시킬 수 있는 실무적 시사점을 제안하였다는 것에 의의가 있다.

핵심어: 염방채 선택속성, SNS 정보특성, 만족도, 충성도

\section{1. 서론}

특정 지역을 상징하는 전통음식은 국가나 지역의 문화 개체로써 고유한 전통 문화와 역사성을 갖고 있다. 또한 지역 주민들의 정체성과 가치에 직접적, 간접적으로 영향을 미치며 지역 경제와 국가 경제 활성화에 기여하게 된다[1]. 세계관광기구(UNWTO)는 전통음식을 국가 브랜드 혹은 이미지를 형성하는 주요 문화 콘텐츠이며 자원으로 해석하였다[1]. 음식 자원으로 해석되는 전통음식은 문화를 체험할 수 있는 기회 제공의 매개체 역할을 담당하기도 한다[1].

염방채(盐帮菜; yan bang cai, 이하 염방채라 칭함)는 천 년 동안 소금의 도시로 널리 알려진 쓰촨성 쯔궁시에서 염방(소금을 생산하는 조직체) 사람들이 모여 만든 음식이다. 소금을 생산하기 위해 다양한 지역의 소금 상인들이 모여 그들의 생활양식과 음식문화가 어우러져 탄생한 것이다. 그러므로 염방채는 쓰촨성 쯔궁시의 고유문화와 역사가 담겨있는 전통음식으로 지역주민들이 즐겨먹는 음식이다. 타 지역과 차별화된 쯔궁시의 문화유산으로 외래 관광객들의 주요 관광 콘텐츠이기도 하다. 수천 년 동안 쓰촨성 쯔궁시는 소금을 생산하며 염방요리를 판매하는 요식업이 발달함으로써 쯔궁시의 무역과 관광 산업을 촉진 시키고 새로운 일자리 창출과 더불어 지역경제에도 기여하였다.

염방채는 전통음식이라는 문화 소비와 관광 콘텐츠에 새로운 트렌드를 제공하고 있다. 요식업체들은 염방채의 다양한 정보를 $\mathrm{TV}$, 신문, 브로슈어 등의 대중매체를 통해 
소비자들에게 전달하였다. 그러나 최근에는 인터넷과 미디어의 발달로 인해 정보 전달의 매개체에도 변화가 찾아왔다. 요식업체들은 소비자들에게 디지털 미디어를 활용하여 유용하고 새로운 정보를 신속하게 제공하고 있다. 모바일과 APP을 이용한 Social Network Service(이하 SNS라 칭함)에 염방채 정보를 다양한 콘텐츠로 제공하며 온라인 커뮤니티를 형성하고 있다. Weibo와 WeChat을 활용한 미디어 커뮤니케이션과 Bili Bili, Douyin 등 기타 비디오 플랫폼을 통해 소비자들과 소통하며 관계를 형성하고 있다.

최근 딜리버리 앱 메이투안와이마이(美团外卖)와 어러머(饿了吗)을 활용한 배달 음식 문화가 급격히 성장하고 있다. iiMedia Research에 의하면 2020년 중국 음식 배달 거래량은 171.2 억 건으로 전년 동기 대비 $7.5 \%$ 증가하였다고 한다[2]. 스마트폰의 보급과 확산에 따라 딜리버리 앱을 이용한 음식 주문 문화가 18 25세대의 젊은층에서 빠르게 확산되고 있는 것이다[3]. 이러한 플랫폼들은 빅데이터를 활용하여 요식업체의 음식 제조 시간과 배송 노선 그리고 배송 예상 시간을 분석하여 소비자들에게 최적의 배송 서비스를 제공하고자 노력하고 있다[3]. 모바일과 APP을 활용한 염방채 정보전달과 배달 서비스는 중국의 외식산업 성장과 요식업체의 경영 패러다임에 새로운 기회를 제공하고 있다.

이상의 논점을 토대로 본 연구에서는 쓰촨성 쯔궁시의 고유 문화와 관광 콘텐츠로 성장하고 있는 염방채와 $\mathrm{SNS}$ 를 활용한 외식산업의 발전을 위해 다음과 같은 연구목적을 설정하였다. 첫째, 오랫동안 전통음식으로 자리매김한 염방채의 선택 속성과 염방채의 정보를 제공하고 있는 SNS 특성은 어떠한지 확인하고자 한다. 둘째, 염방채의 선택 속성과 SNS의 정보 특성은 소비자 만족도와 브랜드 충성도에 어떠한 영향을 미치는지 확인하고자 한다. 넷째, 염방채의 선택 속성과 SNS 정보 특성은 소비자 만족도를 매개하여 브랜드 충성도에 어떠한 영향을 미치는지 이들 변인간의 관계를 확인하고자 한다. 이상의 연구는 전통음식 염방채의 정체성과 가치성을 확인하고 소비자 만족도와 브랜드 충성도를 향상 시키기 위한 염방채 선택 속성과 $\mathrm{SNS}$ 의 정보 특성을 고려한 학문적 함의와 염방채 산업을 발전시키기 위한 실무적 시사점을 제공하고자 한다.

\section{2. 이론적 배경}

\section{1 염방채의 개념과 특성}

쓰촨성에서 가장 부유한 땅으로 알려진 쯔궁시는 소금으로 이루어진 도시라고 불릴 만큼 소금 생산량이 풍부한 지역이다[4]. 쯔궁은 고생대 바다에 잠겨 있다. 중생대 히말라야 조산운동으로 인해 지금의 대륙을 형성한 지형적 특성을 갖고 있다[5]. 이러한 지리적 특성으로 인해 지하에서 염수를 퍼 올려 소금을 생산하며 중국 최대의 소금 생산 지역으로 성장하였다. 쯔궁지역의 정염은 동한 시대에 시작하여 당나라와 송나라, 청나라까지 명성을 떨치며 소금 생산의 중심지로 성장하였다. 중국과 해외까지 명성을 떨치며 성장한 쯔궁지역은 염방으로 인한 경제 성장과 더불어 다양한 지역에서 염업 관련 종사자들이 몰려 불화성을 이루며 성장하였다. 이들로 인해 다양한 지역의 생활양식과 음식문화가 만나 쯔궁시의 독특한 염방채 즉, 염방요리가 탄생하였다.

염방채는 신선하고 자극적인 맛이 특징이다. 쓰촨성을 대표하는 자극적인 매운맛과 단맛, 신맛 등의 다채로운 맛과 특유의 진하고 깊은 풍미를 가진 품격있는 요리로 평가받고 있다. 쯔궁의 풍부한 작물과 신선한 식재료를 이용하여 만든 염방채는 식품안전평가에서 품질 우수성을 인정받으며 쯔궁시 요식업을 대표하는 브랜드로 
성장하였다. 이러한 맥락에서 최근 염방채 판매자들은 메뉴와 맛의 다양화 그리고 퓨전요리를 개발하며 소비자들의 다양한 욕구에 부합하는 다채로운 요식업체로 변화하고 있다.

\section{2 선택속성}

속성은 일반적으로 사물에 내재된 본질적인 성질이나 특징을 의미한다[6]. 선택속성은 제품이나 서비스의 여러 속성 중 소비자의 선호도나 구매행동 결정, 재 구매 의사 등 선택과정에 영향을 미치는 속성을 의미한다[7]. 소비자들은 특정 제품이나 서비스를 선택할 때 많은 속성을 고려하여 선택한다. 이러한 선택속성은 소비자 개인마다 그 중요도와 만족도에 차이가 있다. 특히 음식을 판매하는 요식업체를 선택할 경우 자신의 욕구와 필요에 따라 의사결정 과정에서 중요도와 만족도를 고려한 선택이 이루어진다.

일반적으로 소비자들은 요식업체를 선택하기 위해 개인의 중요도에 따라 맛과 품질, 서비스, 메뉴의 다양성 등을 고려한다. 요식업체 방문 후 소비자들은 이러한 요인들을 평가하며 만족도와 재방문을 결정한다. 이러한 맥락에서 소비자들의 요식업체 선택속성과 그에 따른 행동 연구를 살펴보면 다음과 같다.

한식당의 선택속성과 소비자 태도와의 관계를 살펴본 최인식과 조준호[8]는 음식의 질과 서비스, 분위기, 가격 등이 한식당의 선택요인이라고 설명하였다. 또한 한식당의 선택요인은 소비자의 지각된 가치와 고객 만족도 그리고 재방문 의도에 호의적인 영향이 미친다고 설명하였다. 진은경 등[9]은 소비자들의 외식 소비성향에 따른 한식당의 선택속성을 확인하였다. 그 결과 음식의 품질, 종업원의 서비스, 접근성, 가격할인 요인으로 확인되었다. 또한 음식의 품질과 종업원의 서비스는 소비자 행동 의도에 호의적인 영향이 미치는 것으로 하였다. 그러나 가격할인과 식당의 접근성은 행동 의도에 영향이 미치지 않는 것으로 확인되었다. 서광열과 김동주[10]의 연구에서는 레스토랑의 매력성과 직원의 서비스, 이용의 편의성, 음식의 가치와 맛 그리고 가격이 레스토랑 이용 시 느끼는 즐거움과 쾌락을 주는 소비 감정과 고객만족도에 유의미한 영향이 미치는 것으로 확인되었다.

선행연구를 정리하면 외식업체를 선택하는 요인은 음식의 맛과 품질, 가치 그리고 종업원의 서비스 그 외 외식업체의 매력성과 가격 등으로 확인되었다. 이를 토대로 본 연구에서는 소비자 만족도와 구매 행동에 영향이 미칠 수 있는 선택속성으로 염방채의 역사와 독특한 문화를 담고 있는 전통성과 음식의 맛과 가치를 평가하는 품질 그리고 요식업체의 서비스 외 염방채의 가격과 양의 적절성을 구성요인으로 고려하고자 한다.

\subsection{SNS 정보특성}

디지털 기술의 발달과 스마트 기기의 보급은 SNS를 등장시켰다. 이러한 SNS는 기업과 소비자들에게 다양한 혜택과 편리함을 제공하고 있다. 기업은 전통적인 마케팅 접근에서 벗어나 또 다른 마케팅 도구로 활용할 기회를 제공 받았다. SNS를 통해 정보를 제공하고 잠재 고객과 소통하며 소비자 접점을 만드는 마케팅 도구로써 $\mathrm{SNS}$ 의 영향력은 점점 커지고 있다.

$\mathrm{SNS}$ 는 인터넷을 기반으로 사용자 간 자유로운 의사소통, 정보 공유 그리고 사회적 관계를 형성하고 강화시켜주는 플랫폼 서비스이다[11]. 이러한 특성을 갖고 있는 SNS는 외식업체들에게도 마케팅을 활성화시키기 위한 커뮤니케이션 도구로 널리 활용되고 
있다. 특히 $\mathrm{MZ}$ 세대가 새로운 소비주도층으로 부상하면서 맛과 메뉴, 인증사진, 후기 등의 다양한 시각적 요소와 정보는 소비자 의사결정에 커다란 영향을 미치고 있다.

소비자들은 일상에서 시간과 공간제약이 없는 편리성과 접근의 용이성으로 $\mathrm{SNS}$ 에 접속한다. 구매를 결정할 때 소비자들은 소비 활동의 위험성을 감소시키고 가치 극대화를 위해 SNS를 이용하며 정보를 획득하거나 공유한다[12]. 또한 관심 있는 제품이나 기업 정보를 획득하고자 할 때 $\mathrm{SNS}$ 를 통해 다른 사용자들의 이용 경험이나 전문가들의 리뷰를 확인한다[13]. 확인된 정보는 소비자 의사결정에서 유용하게 사용된다.

이러한 시대적 특성에 따라 최근 $\mathrm{SNS}$ 의 정보 특성에 관한 연구가 다수 진행되고 있다. Delone와 McLean[13]은 정보시스템 관점에서 SNS의 특성을 살펴보며 이를 구성하고 있는 요인을 접근성, 연결성, 정보성, 신뢰성, 유용성, 신뢰성으로 제시하였다. 김기영 등[14]은 외식정보를 제공하는 $\mathrm{SNS}$ 의 특성을 정보최신성, 정보유희성, 정보제공성, 사용편리성, 상호작용성으로 제시하였다. 또한 SNS 특성의 사용편리성과 정보제공성, 정보유희성이 소비자 행동의도와의 관계에 호의적인 영향이 미친다고 하였다. SNS 정보특성이 음식관광의 정보만족과 정보공유의도에 미치는 영향을 살펴본 서민정 등[15]은 $\mathrm{SNS}$ 의 정보 특성을 신뢰성, 상호작용성, 최신성, 정확성으로 제시하였다. 이러한 요인 중 신뢰성, 상호작용성, 정확성은 정보 만족에 긍정적인 영향을 미친다고 하였다. SNS에서 공유된 음식 정보가 정확하고 확실할 때 소비자 만족도가 높다는 결론을 제시하였다.

이상의 논점을 살펴보면 소비자들은 $\mathrm{SNS}$ 를 이용한 정보 선택이 능동적 행태를 보이고 있는 것으로 확인된다. 따라서 본 연구에서 중국 쓰촨성 쯔궁의 전통음식 염방채 정보를 $\mathrm{SNS}$ 를 통해서 획득할 때 소비자들은 $\mathrm{SNS}$ 의 어떠한 정보 특성을 활용하는지, 이러한 $\mathrm{SNS}$ 정보 특성은 소비자 만족도와 브랜드 충성도에 어떠한 영향을 미치는지 확인하고자 한다.

\section{3. 연구가설}

염방채는 쯔궁시의 오랜 역사와 전통을 체험하고 느낄 수 있는 문화유산이자 관광자원이다. 최근 외식업의 다원화가 가져온 개방과 개혁 그리고 경쟁으로 인해 염방채는 쯔궁시의 대표 브랜드로 차별화된 마케팅 전략을 모색하고자 외식업체들은 노력하고 있다. 맛과 메뉴의 다양화 그리고 퓨전 요리를 통해 소비자 욕구에 적합한 맞춤형 서비스를 제공하고자 노력하고 있다. 또한 외식문화 발전에 따라 외식 콘셉트 개발과 식당 환경과 서비스 품질 개선 등으로 소비자 욕구와 만족도 향상을 위해 브랜드 충성도를 제고시키고자 노력하고 있다.

최근 요식업체들은 SNS를 활용한 염방채의 신속하고 새로운 정보제공과 커뮤니티를 형성하며 소비자들과 지속적인 관계를 형성하고 있다. 또한 딜리버리 앱을 활용한 배달 서비스 도입으로 염방채 판매를 가속화 시키고 있다. 이러한 맥락에서 본 연구에서는 소비자들의 염방채 선택속성과 염방채 정보를 확인하기 위해 사용하는 $\mathrm{SNS}$ 의 정보특성은 무엇인지 확인 후 이들 속성이 소비자 만족도와 브랜드 충성도에 미치는 영향과 변인간의 관계성을 확인하고자 다음과 같은 연구가설을 설정하였다.

가설 1. 염방채 선택속성은 소비자 만족도에 정 $(+)$ 의 영향을 미칠 것이다.

가설 2. 염방채 선택속성은 브랜드 충성도에 정 $(+)$ 의 영향을 미칠 것이다.

가설 3. SNS 정보특성은 소비자 만족도에 정 $(+)$ 의 영향을 미칠 것이다.

가설 4. SNS 정보특성은 브랜드 충성도에 정 $(+)$ 의 영향을 미칠 것이다. 
가설 5. 염방채 선택속성은 소비자 만족도를 매개하여 브랜드 충성도에 정 $(+)$ 의 영향을 미칠 것이다.

가설 6. $\mathrm{SNS}$ 정보특성은 소비자 만족도를 매개하여 브랜드 충성도에 정(+)의 영향을 미칠 것이다.

\section{3. 연구 방법}

\section{1 표본선정 및 자료수집}

본 연구를 위한 표본은 중국의 쓰촨성 쯔궁시 거주자들 중 최근 6개월 이내 염방채를 먹어 본 소비자들로 구성하였다. 염방채는 중국의 쓰촨성 쯔궁시민들 모두가 즐겨 먹는 전통음식이다. 그러므로 설문에 참석한 응답자는 20 대 이상의 쯔궁시민들을 대상으로 실시하였다. 응답자 특성을 살펴보면 30세 미만 133 명(44.9\%), 30세 40세 미만 74명 (25.0\%), 40세 49세 미만 55명(18.6\%), 50세 이상이 34명(11.55)이다. 이들의 성별은 남성 147 명(49.7\%), 여성 149 명(50.3\%)으로 구성하였다. 설문조사는 2020년 1월 1차 조사와 2021년 7월 2차 조사로 이루어졌다. 1 2차 기간 동안 이루어진 설문조사 자료는 총 302 부이다. 설문조사 자료 중 불성실한 응답을 제외한 296부를 최종 분석 자료로 활용하였다.

\section{2 변수의 조작적 정의 및 측정}

\subsection{1 염방채 선택속성}

선택속성은 일반적으로 유무형의 제품이 가진 특성을 고려하여 의사결정 할 때 선택하는 요인이다[16]. 그러므로 쯔궁시의 전통음식 염방채를 선택하는 속성은 음식의 품질, 전통성, 서비스, 양과 가격의 적절성으로 정의하였다. 이를 측정하기 위한 문항은 김현동[17]과 이홍구[18]의 연구에서 사용한 측정도를 본 연구에 맞게 수정 및 보완하여 16 개 문항을 구성하였다. 이들 문항의 내적일치도는 Cronbach's $\alpha=.855$ 로 확인하였다.

\subsubsection{SNS 정보특성}

SNS 정보특성은 사회적 관계를 형성하고 강화시켜주는 온라인 플랫폼에서 제공받을 수 있는 정보의 가치효율성으로 정의하였다. 이를 측정하기 위한 문항은 이계선[19]과 정선미, 김영훈[12]의 연구에서 사용한 척도를 본 연구에 맞게 수정 및 보완하여 16 개 문항을 구성하였다. 이들 문항의 내적일치도는 Cronbach's $\alpha=.844$ 로 확인하였다.

\subsection{3 만족도}

만족도는 염방채와 SNS 정보를 평가하고 구매하는 과정에서 갖는 호의적인 느낌으로 정의하였다. 이를 측정하고자 서귀생[20]의 연구에서 사용한 척도를 본 연구에 맞게 수정 및 보완하여 3 개의 문항을 구성하였다. 이들 문항의 내적일치도는 Cronbach's $\alpha=.902$ 로 확인하였다.

\subsection{4 충성도}

충성도는 염방채 브랜드에 대해 재구매와 우선적 선택 그리고 다른 사람에게 추천하고자 하는 소비자 의도로 정의하였다. 이를 측정하기 위하여 임지현 등[21]이 
개발한 척도를 본 연구에 맞게 수정 및 보완하여 4 개의 문항을 구성하였다. 이들 문항의 내적일치도는 Cronbach's $\alpha=.883$ 으로 확인하였다.

\section{3 분석방법}

본 연구를 위한 분석 방법은 다음과 같다. 첫째, 인구통계학적 특성을 확인하고자 기술통계의 빈도 분석을 활용하였다. 둘째, 염방체 선택속성과 SNS 정보특성의 요인을 확인하고자 탐색적 요인분석을 활용하였다. 셋째, 가설 검증을 위해 다중회귀분석과 매개회귀분석을 활용하였다.

\section{4. 분석결과}

\section{1 염방채 선택속성과 SNS 정보특성}

염방채 선택속성 변인을 구성하고 있는 항목들의 타당성 검증과 구성요인을 찾고자 탐색적 요인분석을 실시하였다. 분석결과는 [표 1]과 같다.

[표 1] 염방채 선택속성 요인분석

[Table 1] Factor Analysis of Federal Selection Attributes

\begin{tabular}{|c|c|c|c|c|c|c|}
\hline 요인명 & 측정항목 & $\begin{array}{c}\text { 요인 } \\
\text { 적재량 }\end{array}$ & 공통성 & 고유값 & $\begin{array}{l}\text { 분산 } \\
\text { 비율 }\end{array}$ & 신뢰도 \\
\hline \multirow{5}{*}{ 품질 } & 염방채는 특별한 가치가 있다 & .676 & .511 & \multirow{5}{*}{5.137} & \multirow{5}{*}{32.104} & \multirow{5}{*}{.869} \\
\hline & 염방채는 맛이 좋다 & .649 & .552 & & & \\
\hline & 염방채의 전문성이 느껴진다 & .647 & .541 & & & \\
\hline & 염방채 재료는 신선하다 & .574 & .500 & & & \\
\hline & 염방채는 평판이 좋다 & .509 & .523 & & & \\
\hline \multirow{5}{*}{ 전통성 } & 염방채는 전통적이다. & .786 & .661 & \multirow{5}{*}{1.709} & \multirow{5}{*}{10.680} & \multirow{5}{*}{.846} \\
\hline & 염방채는 향토성이 있다. & .701 & .543 & & & \\
\hline & 염방채는 중국적인 독특함이 있다. & .687 & .559 & & & \\
\hline & 염방채는 역사성 있다. & .652 & .555 & & & \\
\hline & 염방채에서 중국 문화를 느낄 수 있다 & .558 & .627 & & & \\
\hline \multirow{3}{*}{ 서비스 } & 종업원은 메뉴 정보를 잘 알고 있다 & .708 & .606 & \multirow{3}{*}{1.212} & \multirow{3}{*}{7.572} & \multirow{3}{*}{.791} \\
\hline & 메뉴는 이해하기 쉽게 되어 있다. & .702 & .559 & & & \\
\hline & 종업원은 친절하게 서비스를 제공한다 & .676 & .657 & & & \\
\hline \multirow{3}{*}{ 적절성 } & 염방채를 신뢰한다. & .783 & .664 & \multirow{3}{*}{1.017} & \multirow{3}{*}{6.356} & \multirow{3}{*}{.821} \\
\hline & 염방채 가격은 적당하다 & .505 & .546 & & & \\
\hline & 염방채의 양은 적당하다 & .485 & .467 & & & \\
\hline \multicolumn{7}{|c|}{ Kaiser-Meyer-Olkin $=.857$, Bartlettsphericity test $\chi^{2}=1370.373(\mathrm{df}=120, \mathrm{p}<.001)$} \\
\hline
\end{tabular}

변수의 요인을 추출하고자 주성분 분석과 각 요인의 특성을 확인하기 위해 베리멕스 회전법을 활용하였다. 변수와 요인 간의 상관관계 정도를 확인 위한 요인 적재량과 변수에서 추출된 요인들의 분산을 확인하기 위한 공통성 기준은 각각 .40 이상으로 설정하였다. 선택 요인이 변수의 정보를 어느 정도 설명하는지 나타내는 고유값은 1.0 이상으로 설정하였다. 데이터의 적합성을 검증하기 위하여 Kaiser Meyer Olkin를 확인한 결과 .857로 확인되었다. 요인분석의 모형 적합성을 확인하고자 Bartlet의 구형성을 검정한 결과 1370.373으로 확인되었다. 이를 토대로 요인분석을 실시한 결과 염방채 선택속성은 
4 개의 요인으로 도출되었다. 분석 결과는 [표 1]과 같다. 제 1 요인은 염방채는 맛과 평판이 좋으며 전문성이 느껴져 특별한 가치가 있다는 문항으로 구성되어 있음을 확인하였다. 이를 토대로 제 1 요인은 품질로 명명하였다. 제 2 요인은 염방채의 전통성, 향토성, 역사성 그리고 중국의 독특한 문화적 가치를 느낄 수 있다는 항목으로 구성되어 있음을 확인하였다. 이를 토대로 제 2요인은 전통성으로 명명하였다. 제 3 요인은 염방채 메뉴는 이해하기 쉽게 제시되어 있으며 종업원은 메뉴 정보를 잘 알고 친절한 서비스를 제공한다는 항목으로 구성되어 있음을 확인하였다. 이를 토대로 제 3요인은 서비스로 명명하였다. 제 4 요인은 염방채의 가격과 양이 적당하며 신뢰한다는 항목으로 구성되어 있었다. 이를 토대로 제 4요인은 적절성으로 명명하였다.

$\mathrm{SNS}$ 정보특성 변인들을 구성하고 있는 항목들의 타당성 검증과 구성요인을 찾고자 탐색적 요인분석을 실시하였다. 분석 결과는 [표 2]와 같다.

\section{[표 2] SNS 정보특성 요인분석}

[Table 2] SNS Information Characteristic Factor Analysis

\begin{tabular}{|c|c|c|c|c|c|c|}
\hline 요인명 & 측정항목 & $\begin{array}{c}\text { 요인 } \\
\text { 적재 } \\
\text { 량 }\end{array}$ & $\begin{array}{l}\text { 공통 } \\
\text { 성 }\end{array}$ & $\begin{array}{l}\text { 고유 } \\
\text { 값 }\end{array}$ & $\begin{array}{l}\text { 분산 } \\
\text { 비율 }\end{array}$ & $\begin{array}{l}\text { 신뢰 } \\
\text { 도 }\end{array}$ \\
\hline \multirow{5}{*}{ 신뢰성 } & SNS에서 제공되는 염방채 정보는 신속하게 제공된다 & .714 & .599 & \multirow{5}{*}{4.746} & \multirow{5}{*}{$\begin{array}{c}31.63 \\
8\end{array}$} & \multirow{5}{*}{.808} \\
\hline & $\begin{array}{c}\mathrm{SNS} \text { 에서 제공되는 염방채 정보는 대체로 오류가 적은 } \\
\text { 편이다 }\end{array}$ & .658 & .534 & & & \\
\hline & SNS에서 제공되는 염방채 정보는 신뢰할 만하다 & .568 & 410 & & & \\
\hline & SNS에서 제공되는 염방채 정보는 대체로 일관성이 있다 & .542 & .452 & & & \\
\hline & SNS에서 제공되는 염방채 정보는 믿음이 간다 & .489 & .466 & & & \\
\hline \multirow{4}{*}{$\begin{array}{l}\text { 상호 } \\
\text { 작용성 }\end{array}$} & SNS를 통해 염방채 판매자와 커뮤니케이션이 원활하다 & .726 & .554 & \multirow{4}{*}{1.390} & \multirow{4}{*}{9.265} & \multirow{4}{*}{.822} \\
\hline & SNS에서 제공되는 염방채 정보는 내용이 충실하다 & 679 & .558 & & & \\
\hline & $\begin{array}{c}\mathrm{SNS} \text { 에서 제공하는 정보는 내가 다른 사용자와 관계를 맺는 } \\
\text { 기회를제공한다 }\end{array}$ & .663 & .613 & & & \\
\hline & SNS에서 제공하는 염방채 정보 출처를 알 수 있다 & .579 & .529 & & & \\
\hline \multirow{3}{*}{ 유용성 } & SNS에서 제공되는 염방채 정보는 나에게 유용하다 & .800 & .704 & \multirow{3}{*}{1.121} & \multirow{3}{*}{7.474} & \multirow{3}{*}{.863} \\
\hline & $\mathrm{SNS}$ 에서 제공되는 염방채 정보는 나에게 가치가 있다 & .713 & .624 & & & \\
\hline & $\begin{array}{c}\text { SNS에서 제공되는 염방채 정보는 대체로 정확해서 유용하게 } \\
\text { 활용할 수 있다 }\end{array}$ & .615 & .594 & & & \\
\hline \multirow{3}{*}{ 최신성 } & SNS에서 염방채 정보는 지속적으로 업데이트 된다 & .799 & 694 & \multirow[t]{3}{*}{1.014} & \multirow[t]{3}{*}{6.760} & \multirow[t]{3}{*}{.794} \\
\hline & SNS에서 염방채의 새로운 정보를 얻게 된다 & .694 & .542 & & & \\
\hline & SNS에서 염방채의 최신정보를 확인할 수 있다 & .477 & .495 & & & \\
\hline
\end{tabular}

SNS 정보특성의 요인추출 방법은 주성분 분석과 각 요인의 특성을 확인하기 위해 베리멕스 회전법을 활용하였다. 요인 도출을 위해 요인 적재량과 공통성의 기준은 각각 40 이상으로 설정하였다. 요인분석 결과 $\mathrm{SNS}$ 정보특성은 4 개의 요인으로 도출되었다. 제 1 요인을 구성하고 있는 항목은 정보의 오류가 적고 새롭고 신속하며 신뢰할 만한 정보 등으로 구성되어 있음을 확인하였다. 이를 토대로 제 1 요인은 신뢰성으로 명명하였다. 제 2 요인은 $\mathrm{SNS}$ 를 통해 염방채 판매자와 커뮤니케이션이 원활하며 염방채 구매자들과 사회적 관계 기회가 제공된다는 항목 등으로 구성되어 
있음을 확인하였다. 이를 토대로 제 2요인은 상호작용성으로 명명하였다. 제 3 요인은 $\mathrm{SNS}$ 에서 제공되는 정보가 유용하며 가치가 있다는 항목 등으로 구성되었음을 확인하였다. 이를 토대로 제 3요인은 유용성으로 명명하였다. 제 4요인은 SNS에서 새로운 정보를 얻을 수 있으며 염방채의 최신정보를 확인할 수 있다는 항목 등으로 구성되어 있음을 확인하였다. 이를 토대로 제 4요인은 최신성으로 명명하였다.

\section{2 염방채 선택속성이 소비자 만족도 미치는 영향}

염방채 선택속성이 소비자 만족도에 영향이 미친다는 가설을 검증하고자 다중회귀분석을 사용하였다. 분석결과는 [표 3]과 같다. 회귀분석을 실시하기 위하여 종속변수의 자기상관 관계와 독립변수들의 다중공선성을 검증하였다. Durbin-Watson 지수를 이용하여 종속변수의 자기상관 관계를 확인한 결과 2.10 나타났기에 자기상관 관계가 없는 것으로 확인하였다. 다중공선성을 검증하기 위해 VIF 지수를 확인한 결과 10 미만으로 나타났기에 다중공선성이 없는 것으로 확인하였다. 독립변수의 종속변수 설명량 $\mathrm{R}^{2}$ 은 .462 이며 수정된 $\mathrm{R}^{2}$ 은 .455 로 확인하였다. 이를 토대로 염방채 선택속성 요인이 소비자 만족도에 미치는 영향을 확인하였다. 분석결과 품질 $(\mathrm{t}=4.476, \mathrm{p}<.001)$, 적절성 $(\mathrm{t}=4.553, \mathrm{p}<.001)$, 전통성 $(\mathrm{t}=4.611, \mathrm{p}<.001)$, 서비스 $(\mathrm{t}=2.712, \mathrm{p}<.01)$ 요인 모두 정 $(+)$ 의 영향이 미치는 것으로 나타났다. 이상의 연구 결과에 따라 가설 1 은 채택 되었음을 확인하였다.

[표 3] 염방채 선택속성이 소비자 만족도에 미치는 영향

[Table 3] The Effect of YanBang Dishes' Choice Attributes on Customer Satisfaction

\begin{tabular}{|c|c|c|c|c|c|c|}
\hline \multirow{2}{*}{ 모형 } & \multicolumn{2}{|c|}{ 비 표준화계수 } & \multirow{2}{*}{ 표준화 계수 } & \multirow{2}{*}{$\mathrm{t}$} & \multicolumn{2}{|c|}{ 공선성 통계량 } \\
\cline { 2 - 3 } \cline { 6 - 7 } & $\mathrm{B}$ & 표준오차 & 베타 & & 공차 & $\mathrm{VIF}$ \\
\hline 품질 & .282 & .063 & .268 & $4.476^{* * * *}$ & .516 & 1.939 \\
\hline 전통성 & .239 & .052 & .238 & $4.611^{* * *}$ & .692 & 1.445 \\
\hline 서비스 & .141 & .052 & .130 & $2.712^{* *}$ & .807 & 1.239 \\
\hline 적절성 & .323 & .071 & .248 & $4.553^{* * *}$ & .623 & 1.604 \\
\hline
\end{tabular}

***p $<.001, * * \mathrm{p}<.01, * \mathrm{p}<.05 \quad \mathrm{~F}=62.594(\mathrm{p}<.001)$ Durbin-Watson $=2.10$

\section{3 염방채 선택속성이 브랜드 충성도에 미치는 영향}

염방채 선택속성이 브랜드 충성도에 영향이 미친다는 가설 검증을 위하여 다중회귀분석을 사용하였다. 분석결과는 [표 4]와 같다. 다중회귀분석을 실시하기 위하여 종속변수의 자기상관 관계와 독립변수들의 다중공선성을 검증하였다. Durbin-Watson 지수를 이용하여 종속변수의 자기상관 관계를 확인한 결과, 1.731 로 나타났기에 자기상관 관계가 없는 것으로 확인하였다. VIF 지수를 확인한 결과, 10 미만으로 나타났기에 다중공선성이 없는 것으로 확인하였다. 독립변수의 종속변수 설명량 $\mathrm{R}^{2}$ 은 .515 이며 수정된 $\mathrm{R}^{2}$ 은 .508로 확인하였다. 이를 토대로 염방채 선택속성 요인이 브랜드 충성도에 미치는 영향을 확인한 결과 전통성 $(\mathrm{t}=7.610, \mathrm{p}<.001)$, 품질 $(\mathrm{t}=5.583, \mathrm{p}<.001)$, 적절성 $(\mathrm{t}=2.274$, $\mathrm{p}<.05)$, 서비스 $(\mathrm{t}=2.030, \mathrm{p}<.05)$ 요인 모두 정 $(+)$ 의 영향을 미치는 것으로 나타났다. 이상의 결과를 정리하면 가설 2는 채택되었음을 확인하였다. 
The Effect of YanBang Dishes Selection Attributes and SNS Information Characteristics in China on Brand Loyalty: Focusing on the Mediating Effect of Consumer Satisfaction

[표 4] 염방채 선택속성이 브랜드 충성도에 미치는 영향

[Table 4] Effect of YanBang Dishes' Choice Attributes on Brand Loyalty

\begin{tabular}{|c|c|c|c|c|c|c|}
\hline \multirow{2}{*}{ 모형 } & \multicolumn{2}{|c|}{ 비 표준화계수 } & \multirow{2}{*}{$\begin{array}{c}\text { 표준화 계수 } \\
\text { 베타 }\end{array}$} & \multirow{2}{*}{$\mathrm{t}$} & \multicolumn{2}{|c|}{ 공선성 통계량 } \\
\hline & B & 표준오차 & & & 공차 & VIF \\
\hline 품질 & .336 & .060 & .317 & $5.583 * * *$ & .516 & 1.939 \\
\hline 전통성 & .378 & .050 & .374 & $7.610^{* * *}$ & .692 & 1.445 \\
\hline 서비스 & .101 & .050 & .092 & $2.030^{*}$ & .807 & 1.239 \\
\hline 적절성 & .154 & .068 & .118 & $2.274^{*}$ & .623 & 1.604 \\
\hline
\end{tabular}

*** $\mathrm{p}<.001, * \mathrm{p}<.05 \quad \mathrm{~F}=77.237(\mathrm{p}<.001)$ Durbin-Watson=1.731

\subsection{SNS 정보특성이 소비자 만족도에 미치는 영향}

$\mathrm{SNS}$ 정보특성이 소비자 만족도에 영향이 미친다는 가설을 검증하고자 다중회귀분석을 사용하였다. 분석결과는 [표 5]와 같다. 회귀분석을 실시하기 위하여 종속변수의 자기상관 관계와 독립변수들의 다중공선성을 검증하였다. Durbin-Watson 지수 확인 결과 1.663 으로 나타났기에 자기상관 관계가 없는 것으로 확인하였다. 다중공선성을 검증하기 위해 VIF 지수를 확인한 결과 10 미만으로 나타났다. 그러므로 다중공선성이 없는 것으로 확인하였다. 독립변수의 종속변수 설명량 $\mathrm{R}^{2}$ 은 .313이며 수정된 $\mathrm{R}^{2}$ 은 .303으로 확인하였다. 이를 토대로 SNS 정보특성 요인이 소비자 만족도에 미치는 영향을 확인한 결과 유용성 $(\mathrm{t}=3.997, \quad \mathrm{p}<.001), \quad$ 신뢰성 $(\mathrm{t}=3.235, \quad \mathrm{p}<.01), \quad$ 상호작용성 $(\mathrm{t}=2.770, \quad \mathrm{p}<.01)$, 최신성 $(\mathrm{t}=2.217, \mathrm{p}<.05)$ 요인 모두 정 $(+)$ 의 영향을 미치는 것으로 나타났다. 이상의 결과를 정리하면 가설 3은 채택되었음을 확인하였다.

[표 5] SNS 정보특성이 소비자 만족도에 미치는 영향

[ Table 5] Effect of SNS Information Characteristics on Consumer Satisfaction

\begin{tabular}{|c|c|c|c|c|c|c|}
\hline \multirow{2}{*}{ 모형 } & \multicolumn{2}{|c|}{ 비 표준화계수 } & \multirow{2}{*}{ 표준화 계수 } & \multirow{2}{*}{$\mathrm{t}$} & \multicolumn{2}{|c|}{ 공선성 통계량 } \\
\cline { 2 - 4 } \cline { 6 - 7 } & $\mathrm{B}$ & 표준오차 & 베타 & & 공차 & VIF \\
\hline 신뢰성 & .222 & .069 & .209 & $3.235^{* *}$ & .567 & 1.765 \\
\hline 상호작용성 & .164 & .059 & .167 & $2.770^{* *}$ & .649 & 1.541 \\
\hline 유용성 & .208 & .052 & .224 & $3.997^{* * *}$ & .752 & 1.329 \\
\hline 최신성 & .129 & .058 & .129 & $2.217^{*}$ & .693 & 1.442 \\
\hline
\end{tabular}

***p<.001, **p<.01, *p<.05 F=33.072(p<.001) Durbin-Watson $=1.663$

\section{$4.5 \mathrm{SNS}$ 정보특성이 브랜드 충성도에 미치는 영향}

SNS 정보특성이 브랜드 충성도에 영향이 미친다는 가설을 검증하고자 다중회귀분석을 사용하였다. 분석 결과는 [표 6]과 같다. 회귀분석을 실시하기 위하여 종속변수의 자기상관 관계와 독립변수들의 다중공선성을 검증하였다. 검증결과, Durbin-Watson 지수는 $1.734, \mathrm{VIF}$ 지수는 10 미만으로 나타났다. 따라서 자기상관관계와 다중공선성이 없는 것으로 확인하였다. 독립변수의 종속변수 설명량 $\mathrm{R}^{2}$ 은 .370 이며 수정된 $\mathrm{R}^{2}$ 은 .361로 확인하였다. 이를 토대로 SNS 정보특성 요인이 브랜드 충성도에 미치는 영향을 확인한 결과 유용성 $(\mathrm{t}=4.856, \quad \mathrm{p}<.001), \quad$ 상호작용성 $(\mathrm{t}=3.569, \mathrm{p}<.001), \quad$ 신뢰성 $(\mathrm{t}=3.321, \quad \mathrm{p}<.01)$, 
최신성 $(\mathrm{t}=2.151, \mathrm{p}<.05)$ 요인 모두 정 $(+)$ 의 영향을 미치는 것으로 나타났다. 이상의 결과를 정리하면 가설 4는 채택되었음을 확인하였다.

[표 6] SNS 정보특성이 브랜드 충성도에 미치는 영향

[Table 6] The Effect of Information Characteristics of SNS on Brand Loyalty

\begin{tabular}{|c|c|c|c|c|c|c|}
\hline \multirow{2}{*}{ 모형 } & \multicolumn{2}{|c|}{ 비 표준화계수 } & 표준화 계수 & \multirow{2}{*}{$\mathrm{t}$} & \multicolumn{2}{|c|}{ 공선성 통계량 } \\
\cline { 2 - 4 } \cline { 6 - 7 } & $\mathrm{B}$ & 표준오차 & 베타 & & 공차 & VIF \\
\hline 신뢰성 & .220 & .066 & .205 & $3.321^{* *}$ & .567 & 1.765 \\
\hline 상호작용성 & .204 & .057 & .206 & $3.569 * * *$ & .649 & 1.541 \\
\hline 유용성 & .244 & .050 & .261 & $4.856^{* * *}$ & .752 & 1.329 \\
\hline 최신성 & .121 & .056 & .120 & $2.151^{*}$ & .693 & 1.442 \\
\hline
\end{tabular}

$* * * \mathrm{p}<.001, * * \mathrm{p}<.01, * \mathrm{p}<.05 \mathrm{~F}=42.663(\mathrm{p}<.001)$ Durbin-Watson $=1.734$

\section{6 염방채 선택속성과 브랜드 충성도 간에 소비자 만족도 매개효과}

염방채 선택속성이 소비자 만족도를 매개하여 브랜드 충성도에 영향이 미친다는 가설을 검증하고자 매개회귀분석을 사용하였다. 분석 결과는 [표 7]과 같다.

염방채 선택속성 중 품질 요인이 소비자 만족도를 매개하여 브랜드 충성도에 영향이 미치는지 확인하기 위한 1 단계에서는 독립변인의 품질 $(\mathrm{p}<.001), \quad$ 전통성 $(\mathrm{p}<.001)$, 서비스 $(\mathrm{p}<.01)$, 적절성 $(\mathrm{p}<.001)$ 이 소비자 만족도에 유의미한 영향을 미치는 것으로 확인하였다. 염방채의 품질 $(\mathrm{B}=.268)$ 이 높을수록 전통성 $(\mathrm{B}=.238)$, 서비스 $(\mathrm{B}=.130)$, 적절성 $(\mathrm{B}=.248)$ 이 높을수록 소비자 만족도가 높은 것으로 확인하였다. 소비자 만족도를 설명하는 설명량은 $46.2 \%$ 이다. 2 단계에서 독립변인의 품질 $(\mathrm{p}<.001)$, 전통성 $(\mathrm{p}<.001)$, 서비스 $(\mathrm{p}<.05)$, 적절성 $(\mathrm{p}<.05)$ 은 소비자 만족도에 유의미한 영향을 미치는 것으로 확인하였다. 염방채의 품질 $(\mathrm{B}=.317)$ 이 높을수록 전통성 $(\mathrm{B}=.374), \quad$ 서비스 $(\mathrm{B}=.092)$, 적절성 $(\mathrm{B}=.118)$ 이 높을수록 브랜드 충성도가 높은 것으로 확인하였다. 브랜드 충성도를 설명하는 설명량은 $51.5 \%$ 이다. 매개효과 3 단계에서 소비자 만족도는 브랜드 충성도에 유의미한 영향이 미치기에 매개효과가 있는 것으로 확인하였다. 분석 결과를 구체적으로 살펴보면 3 단계에서 서비스( $\mathrm{p}>.05)$ 와 적절성 $(\mathrm{p}>.05)$ 은 유의미한 영향이 미치지 않는 것으로 나타났다. 따라서 소비자 만족도는 서비스와 적절성에서 브랜드 충성도에 미치는 영향에 대하여 완전 매개하는 것으로 확인하였다. 그러나 품질 $(\mathrm{p}<.001)$ 과 전통성 $(\mathrm{p}<.001)$ 은 브랜드 충성도에 유의미한 영향이 미치는 것으로 나타났다. 따라서 소비자 만족도는 품질과 전통성이 브랜드 충성도에 미치는 영향에 대하여 부분 매개하는 것으로 확인하였다. 가설 5는 채택되었음을 확인하였다.

[표 7] 염방채 선택속성과 브랜드 충성 간에 소비자 만족도 매개효과

[Table 7] Influence of YanBang Dishes' Choice Attributes on Brand Loyalty by Mediating Consumer Satisfaction

\begin{tabular}{|c|c|c|c|c|}
\hline \multirow{2}{*}{ 모형 } & 1 단계 & 2단계 & 3단계 & \multirow{2}{*}{ Sobel 검증 } \\
\cline { 1 - 4 } & 소비자 만족도 & 브랜드 충성도 & 브랜드 충성도 & \\
\hline 품질 & $.268^{* * *}$ & $.317^{* * *}$ & $4.011^{* * *}$ & $\mathrm{Z}=3.563(\mathrm{p}<.001)$ \\
\hline 전통성 & $.238^{* * *}$ & $.374^{* * *}$ & $6.073^{* * *}$ & $\mathrm{Z}=3.885(\mathrm{p}<.001)$ \\
\hline
\end{tabular}


The Effect of YanBang Dishes Selection Attributes and SNS Information Characteristics in China on Brand Loyalty: Focusing on the Mediating Effect of Consumer Satisfaction

\begin{tabular}{|c|c|c|c|c|}
\hline 서비스 & $.130^{* *}$ & $.092^{*}$ & 1.029 & $\mathrm{Z}=2.541(\mathrm{p}<.01)$ \\
\hline 적절성 & $.248^{* * *}$ & $.118^{*}$ & .500 & $\mathrm{Z}=3.856(\mathrm{p}<.01)$ \\
\hline 소비자 만족도 & & & $7.316^{* * *}$ & \\
\hline $\begin{array}{c}\mathrm{adj} \mathrm{R}^{2} \\
\mathrm{~F}\end{array}$ & .462 & .515 & .591 & \\
\hline
\end{tabular}

$* * * \mathrm{p}<.001, * * \mathrm{p}<.01, * \mathrm{p}<.05 /$ Durbin-Watson $=1.662$

\subsection{SNS 정보특성과 브랜드 충성도 간에 소비자 만족도 매개효과}

$\mathrm{SN}$ 의 정보특성이 소비자 만족도를 매개하여 브랜드 충성도에 영향이 미친다는 가설을 검증하고자 매개회귀분석을 사용하였다. 분석 결과는 [표 8]과 같다. SNS의 정보특성 중 품질요인이 소비자 만족도를 매개하여 브랜드 충성도에 영향이 미치는지 확인하였다. 이를 위한 1 단계에서 독립변인의 신뢰성 $(\mathrm{p}<.01)$, 상호작용성 $(\mathrm{p}<.01), \quad$ 유용성 $(\mathrm{p}<.001)$, 최신성 $(\mathrm{p}<.05)$ 은 소비자 만족도에 유의미한 영향을 미치는 것으로 확인하였다. 염방채의 신뢰성 $(\mathrm{B}=.209)$, 상호작용성 $(\mathrm{B}=.167)$, 유용성 $(\mathrm{B}=.224)$ 및 최신성 $(\mathrm{B}=.129)$ 이 높을수록 소비자 만족도가 높은 것으로 확인하였다. 소비자 만족도를 설명하는 설명량은 $31.3 \%$ 이다. 2 단계에서 독립변인의 신뢰성 $(\mathrm{p}<.01)$, 상호작용성 $(\mathrm{p}<.001)$, 유용성 $(\mathrm{p}<.001)$, 최신성 $(\mathrm{p}<.05)$ 은 브랜드 충성도에 유의미한 영향을 미치는 것으로 확인하였다. SNS 정보특성 중 신뢰성 $(\mathrm{B}=.205)$, 상호작용성 $(\mathrm{B}=.206)$, 유용성 $(\mathrm{B}=.261)$ 및 최신성 $(\mathrm{B}=.120)$ 이 높을수록 브랜드 충성도가 높은 것으로 확인하였다. 브랜드 충성도를 설명하는 설명량은 $37.0 \%$ 이다. 매개효과 3 단계에서 소비자 만족도는 브랜드 충성도에 유의미한 영향이 미치기에 매개효과가 있는 것으로 확인하였다. 분석 결과를 구체적으로 살펴보면 3 단계에서 신뢰성(p>.05)과 최신성(p>.05)은 유의미한 영향이 미치지 않는 것으로 나타났다. 그러므로 소비자 만족도에서 신뢰성과 최신성은 브랜드 충성도에 미치는 영향에 대하여 완전 매개하는 것으로 확인하였다. 그러나 상호작용성 $(\mathrm{p}<.05)$ 과 유용성 $(\mathrm{p}<.01)$ 은 브랜드 충성도에 유의미한 영향이 미치는 것으로 나타났다. 따라서 소비자 만족도는 상호작용성과 유용성에서 브랜드 충성도에 미치는 영향에 대하여 부분 매개하는 것으로 확인하였다. 가설 6은 채택되었음을 확인하였다.

[표 8] SNS의 정보특성과 브랜드 충성도 간에 소비자 만족도 매개효과

[Table 8] The Effect of Information Characteristics of SNS on Brand Loyalty by Mediating Consumer Satisfaction

\begin{tabular}{|c|c|c|c|c|}
\hline \multirow{2}{*}{ 모형 } & 1 단계 & 2단계 & 3단계 & \multirow{2}{*}{ Sobel 검증 } \\
\cline { 2 - 5 } & 소비자 만족도 & 브랜드 충성도 & 브랜드 충성도 & \\
\hline 신뢰성 & $.209^{* *}$ & $.205^{* *}$ & .103 & $\mathrm{Z}=3.065(\mathrm{p}<.01)$ \\
\hline 상호작용성 & $.167^{* *}$ & $.206^{* * *}$ & $.124^{*}$ & $\mathrm{Z}=2.680(\mathrm{p}<.01)$ \\
\hline 유용성 & $.224^{* * *}$ & $.261^{* * *}$ & $.151^{* *}$ & $\mathrm{Z}=3.719(\mathrm{p}<.001)$ \\
\hline 최신성 & $.129^{*}$ & $.120^{*}$ & .057 & $\mathrm{Z}=2.172(\mathrm{p}<.01)$ \\
\hline 소비자 만족도 & & & $.491^{* * *}$ & \\
\hline $\mathrm{adjR}^{2}$ & .313 & .370 & 635 & \\
$\mathrm{~F}$ & $33.072^{* * *}$ & $42.663^{* * *}$ & $66.804^{* * *}$ & \\
\hline
\end{tabular}




\section{5. 결론 및 논의}

염방채는 중국의 쓰촨성 쯔궁시를 대표하는 전통음식 음식이다. 쓰촨성 쯔궁 시민과 관광객 모두가 즐겨 먹는 전통음식으로써 역사적, 문화적 가치가 매우 높다. 최근 요식업체는 $\mathrm{SNS}$ 를 활용하여 염방채의 다양한 정보를 제공하며 마케팅을 활성화 시키고자 노력하고 있다. 이러한 맥락에 따라 본 연구에서는 중국 쓰촨성의 역사적, 문화적 가치가 높은 염방채 선택 속성을 확인하고 소비자 만족도와 브랜드 충성도에는 어떠한 영향을 미치는지 확인하였다. 또한, 이들 변인 간의 관계는 어떠한지 확인하였다. 염방채의 다양한 정보를 제공하는 $\mathrm{SNS}$ 의 정보특성은 무엇인지 확인하고 소비자 만족도와 염방채 브랜드 충성도에는 어떠한 영향을 미치는지 확인하였다. 또한 이들 변인 간의 관계는 어떠한지 확인하였다.

연구를 위한 요인분석 결과 염방채 선택속성은 품질, 전통성, 서비스, 적절성으로 확인하였다. 염방채의 선택속성은 소비자 만족도에 영향이 미치는 것으로 확인하였다. 이에 따른 함의는 다음과 같다. 먼저, 전문 음식으로 염방채의 맛이 좋을수록 소비자 만족도가 높은 것으로 나타났다. 둘째, 염방채의 적절한 양과 가격 그리고 신뢰감이 높을수록 소비자 만족도가 높은 것으로 나타났다. 셋째, 염방채는 중국의 전통음식이다. 그러므로 중국의 전통성과 역사성 그리고 향토성이 높다고 느낄수록 만족도가 높은 것으로 나타났다. 넷째, 염방채를 먹기 위해 방문하는 식당 종업원의 친절함이나 메뉴 정보를 제공하는 서비스가 높을수록 소비자 만족도가 높은 것으로 사료된다.

염방채의 선택속성이 브랜드 충성도에 영향을 미치는 것으로 나타났다. 이에 따른 함의는 다음과 같다. 먼저, 브랜드 충성도에 가장 크게 영향을 미치는 염방채 선택속성은 중국의 독특함을 대표하며 역사성을 느낄 수 있는 전통성으로 나타났다. 둘째, 염방채의 특별한 가치와 맛 그리고 좋은 평판이 염방채의 품질을 대표하는 속성으로 이러한 속성을 높게 평가할수록 브랜드 충성도가 높은 것으로 나타났다. 셋째, 염방채의 신뢰도와 방문한 식당 종업원의 친절함이나 메뉴 정보의 충실성이 높을수록 브랜드 충성도가 높은 것으로 확인하였다. 그러므로 쯔궁시의 전통음식 염방채의 브랜드 충성도를 높이기 위해서는 염방채의 전통성과 품질 유지 그리고 신뢰성과 판매 식당의 서비스 향상이 고려되어야 할 것이다.

이상의 내용을 토대로 염방채 선택속성과 소비자 만족도 및 브랜드 충성도와의 관계를 확인하였다. 그 결과 소비자 만족도는 염방채 선택속성 중 서비스와 적절성에는 완전 매개효과가 있는 것으로 확인하였다. 그러나 소비자 만족도는 염방채 선택속성 중 품질과 전통성에는 부분 매개효과가 있는 것으로 확인하였다.

$\mathrm{SNS}$ 정보특성을 구성하고 있는 요인은 신뢰성, 상호작용성, 유용성, 최신성으로 확인하였다. SNS 정보특성을 구성하고 있는 요인은 소비자 만족도에 영향을 미치는 것으로 확인하였다. 이에 따른 연구의 함의는 다음과 같다. 첫째, SNS에서 제공하는 염방채 정보의 유용성과 가치성이 높을수록 소비자들은 염방채에 관한 만족도가 높은 것으로 확인하였다. 둘째, $\mathrm{SNS}$ 에서 제공하는 염방채 정보가 신뢰할 만 하거나 새로운 정보를 신속하게 제공하며 정보의 일관성이 있을 때 소비자 만족도가 높은 것으로 확인하다. 셋째, $\mathrm{SNS}$ 를 통해 제공되는 정보 내용이 충실하거나 판매자와 소비자와의 커뮤니케이션이 원활하게 상호작용이 될 경우 소비자 만족도가 높은 것으로 확인하였다. 넷째, $\mathrm{SNS}$ 에서 염방채의 정보가 지속적으로 업데이타 되며 새로운 정보를 얻게 될 때 소비자 만족도가 높은 것으로 확인하였다. 따라서 염방채 만족도를 높이기 위해서는 
염방채 정보를 제공하는 판매자와 소비자와의 $\mathrm{SNS}$ 를 활용한 상호작용성을 높거나 $\mathrm{SNS}$ 에서 제공되는 염방채 정보의 신뢰성과 유용성 그리고 정보의 지속적인 업테이타 제공이 필요함을 사료 드리고자 한다.

염방채 정보의 가치성과 유용성이 높을수록 브랜드 충성도가 높은 것으로 확인하였다. 이에 다른 함의는 다음과 같다. 첫째, $\mathrm{SNS}$ 를 통해 판매자와 소비자와의 원활한 커뮤니케이션과 염방채 정보의 출처와 내용의 충실성이 높을수록 브랜드 충성도가 높은 것으로 확인하였다. 둘째, SNS에서 제공되는 정보의 신속성과 제공되는 정보의 오류가 적거나 일관성 있는 정보를 제공하여 신뢰성이 높아질수록 염방채 브랜드 충성도가 높은 것으로 확인하였다. 셋째, $\mathrm{SNS}$ 에서 제공되는 염방채 정보가 지속적으로 업데이타 되고 제공되는 새로운 정보가 정확하여 유용하게 활용될 경우 브랜드 충성도가 높은 것으로 확인하였다. 염방채 브랜드 충성도를 높이기 위해서는 판매자는 $\mathrm{SNS}$ 를 활용한 소비자와의 상호작용성과 정보의 신뢰성, 유용성, 최신성을 제공하는 것이 효과적인 것으로 사료된다.

이상의 내용을 토대로 염방채 정보를 제공하는 SNS 특성과 소비자 만족도 및 브랜드 충성도와의 관계를 확인하였다. 그 결과 소비자 만족도는 염방채 정보를 제공하는 SNS의 특성 중 신뢰성과 최신성에는 완전 매개효과가 있는 것으로 확인하였다. 그러나 소비자 만족도는 염방채 정보를 제공하는 SNS의 중 상호작용성과 유용성에는 부분 매개효과가 있는 것으로 확인하였다.

연구의 한계점과 제언사항은 다음과 같다. 첫째, 본 연구의 응답자는 최근 6 개월 이내 염방채를 먹어 본 소비자들로 구성하였다. 그러나 시식 경험 횟수나 구매량에 따라서 염방채 선택속성, 만족도, 브랜드 충성도가 달라질 수 있을 것이라는 점을 고려하지 않았다는 한계점을 갖고 있다. 차후 연구에서는 시식 경험 횟수나 구매량을 고려한 연구가 이루져야 함을 제언한고자 한다. 둘째, 염방채는 보편적으로 중국의 쓰촨성 쯔궁시민들이 즐겨 먹는 전통음이자만 소비자 특성에 따라 관여도는 다를 것이다. 그러므로 염방채 관여도에 따라 소비자들의 선택속성이나 만족도, 충성도가 달라질 수 있을 것이라는 점을 고려하지 않은 한계점을 가지고 있다. 차후 연구에서는 연구의 일반화를 위해 소비자 관여도를 고려한 연구가 이루어지길 제언하는 바이다.

\section{References}

[1] Kwang-moo Park, Food tourism promotion plan, Ministry of Culture, Sports and Tourism, pp.1-209, (2013)

[2] Fu Jiawen, The total number of foreign sales orders reached 17.12 billion, and the number of users was close to 500 million. Online catering is expected to account for more than $20 \%$ of the industry, YICAI, News, https://www.yicai.com/news/100898828.html, Jan 01 (2021)

[3] https://news.kotra.or.kr/user/globalBbs/kotranews/782/globalBbsDataView.do?setIdx=243\&dataIdx=189565, Jul 16 (2021)

[4] https://news.kotra.or.kr/user/globalBbs/kotranews/6/globalBbsDataView.do?setIdx=322\&dataIdx=174087, Apr 12 (2019)

[5] http://monthly.chosun.com/client/news/viw.asp?nNewsNumb=201504100052, Apr (2015)

[6] https://ko.wikipedia.org/wiki/\%EC\%86\%8D\%EC\%84\%B1, Jul 20 (2021)

[7] Kyung-Hee Kim, Young-Sook Han, A Study on the Structural Relationships among Selection Attributes, Satisfaction, and Loyalty of Green Tea Consumers: The Moderating Effect of Involvement, Korean Journal of Food and Cookery 
Science, (2011), Vol.27, No.2, pp.83-94, UCI: G704-000460.2011.27.2.005

[8] In Sik Choi, Cho Jun Ho, A Study on the Structural Relationships that Selection Attributes of Korean Restaurants have on Perceived Value, Customer Satisfaction and Revisit Intention - Centered on Exclusive Commercial Area in the Korean Restaurant -, Journal of Foodservice Management, (2016), Vol.19, No.2, pp.7-31, UCI: G704SER000002017.2016.19.2.001

[9] Eun Kyung Jin, Young Hee Park, Jong Ho Lee, The Effect of Attributes of Selecting Korean Restaurants Pursuant to Food Service Consumption Propensity on Behavioral Intent, Culinary Science and Hospitality Research, (2014), Vol.20, No.1, pp.189-204, DOI: 10.20878/cshr.2014.20.1.015

[10] Kwang-Yul Suh, Dong-Soo Kim, The Effect of Restaurant Choice Attributes on Consumption Emotion and Customer Satisfaction, Journal of Foodservice Management, (2011), Vol.14 No.1, pp.115-136, UCI: G704SER000002017.2011.14.1.004

[11] https://ko.wikipedia.org/wiki/\%EC\%86\%8C\%EC\%85\%9C_\%EB\%, Jul 25 (2021)

[12] Seon Mi Jung, Young Hun Kim, A Study on the Effects of SNS Information Characteristics and SNS Site Characteristics on the Intention to Visit a Restaurant, Culinary Science and Hospitality Research, (2015), Vol.21, No.1, pp.159-173, DOI: 10.20878/cshr.2015.21.1.012

[13] W. H. Delone, E. R. McLean, The DeLone and McLean Model of Information Systems Success: A Ten-Year Update, Journal of Management Information Systems, (2003), Vol.19, No.4, pp.9-30, DOI: https://doi.org/10.1080/07421222.2003.11045748

[14] Ki-Young Kim, Min-Kyung Kim, Jae-Ek Sim, A study on the effects of the characteristics of SNS providing foodservice information on perceived value and behavioral, International Journal of Tourism and Hospitality Research, (2016), Vol.30, No.12, pp.179-193, DOI: 10.21298/IJTHR.2016.12.30.12.179

[15] Min-Jung Seo, Ja-Yeon Park, Eun-Soon Yim, The Effect of SNS Information Characteristics of Food Tourism on Information Satisfaction, Information Sharing Intention: In the Case of Chinese Tourist, Journal of MICE \& Tourism Research, (2019), Vol.19, No.4, pp.141-158, DOI: 10.35176/JMTR.19.4.8

[16] Jong Ho Lee, A Study about the Effect of Kimchi Purchasing Selection Features on Purchasing Intent by Food-related LifeStyles of Women- Focusing on Pusan and Ulsan Regions -, Journal of Foodservice Management, (2012), Vol.15, No.5, pp.249-271, UCI: G704-SER000002017.2012.15.5.008

[17] Hyeon-dong Kim, A Study on the Selection Attributes of Bulgogi Korean Restaurants on Customer Satisfaction, Revisit Intention and Recommendation Intention, Graduate School of Tourism \& Hospitality, Kyonggi University, Master's thesis, pp.1-76, (2017)

[18] Heung-Goo Lee, The Effect of the Restaurant Choice Attributes on Consumer Attitude: Focusing on the Mediating Effects of Brand Image and Corporate Image, Graduate school, Honam University, Ph.D dissertation, pp.1-84, (2016)

[19] Gye-Sun Lee, The Effects of Korean Restaurant Selection Attributes and SNS Information Quality on Perceived Value and Behavior Intention, Graduate School of Business Administration Dankook University, Master's thesis, pp.1-81, (2017)

[20] Kwi Saeng Seo, The Effect of SNS Food-service Information Characteristics on Satisfaction, Dissatisfaction and Behavior Intention, Department of Culinary and Food Service Management The Graduate School Sejong University, Ph.D dissertation, pp.1-102, (2017)

[21] Jeehyun Lim, Yunseon Choe, Hak Jun Song, A Study of Causal-Effect Relationships among Functional, Symbolic, Experiential Brand Image, Satisfaction, Trust, and Loyalty: Focused on Family Restaurant Customers, Journal of the Korean Data Analysis Society, (2016), Vol.18, No.6, pp.3251-3268, UCI: G704-000930.2016.18.6.040 